\title{
Análise da evolução do desempenho técnico das equipes brasileiras de alto nível
}

\section{Autores: Laura B. Nicolau (EM), Raiane C. Campos (EM), Rayssa A. Silva (EM), Rayssa F. S. Oliveira (EM), Rafael A. Prochnow (IC), Vitor M. C. Reale (IC), Luciano A. Mercadante (PQ)}

\section{Resumo:}

O trabalho analisou a evolução técnica do Novo Basquete Brasil, temporada 2008/09 a 2011/12. As amostras foram coletadas do site: http://lnb.com.br/, da Liga Nacional de Basquetebol, que apresenta as tabelas dos jogos com os indicadores técnicos coletados online. A partir disso, calculamos as Somas, Médias, Medianas, e porcentagens de eficiência de cada indicador técnico, para comparação de desempenho entre as temporadas. Os lances livres e os arremessos de 2 pontos apresentaram crescimento entre as temporadas, e houve diminuição na utilização dos arremessos de 3 pontos.

\section{Palavras-chave: Basquetebol, indicadores técnicos, alto rendimento esportivo.}

\section{Introdução}

O basquetebol é uma modalidade esportiva que está ganhando espaço no Brasil a cada ano. Com o surgimento da Liga Nacional de Basquete (LNB) e o campeonato Novo Basquete Brasil (NBB), o esporte no país se torna cada vez mais profissional, organizado e competitivo. Dessa forma, os times estão cada vez investindo na preparação para os campeonatos. Assim, informações dos indicadores técnicos que compõem o jogo de basquetebol, como arremesso de dois e três pontos, assistências, rebotes, entre outros $[1,2,3]$, e suas análises, são fundamentais para melhorar o desempenho dos times em quadra e acompanhar a performance dos mesmos ao longo das temporadas. Contudo, não há muitos estudos na literatura sobre os indicadores técnicos no NBB. Dessa forma, nosso estudo tem como objetivo analisar os indicadores técnicos do NBB, ao longo de quatro temporadas com intuído de avaliar as evoluções desses indicadores.

\section{Metodologia}

As planilhas com os indicadores técnicos dos 964 jogos das temporadas de 2008/09 até 2011/12 foram retirados do site oficial da LNB. Em seguida, estruturamos os dados em matrizes, organizadas nos programas LibreOffice e Excel, colocando cada indicador em uma respectiva coluna, para realizarmos as análises em ambiente Matlab ${ }^{\circledR}$. Separamos as matrizes por temporadas, jogos e equipes, sendo cada integrante Ensino Médio do grupo, responsável por uma temporada. Ao final desse processo, calculamos as somas, médias, medianas e desvios padrão de cada indicador em cada temporada, e construímos gráficos de barras para visualização dos resultados por temporada e gráficos boxplot para visualizar a distribuição dos valores de cada indicador por temporada. Construímos uma matriz com todos os indicadores técnicos de todos os jogos, identificando, também, a temporada, o número do jogo na temporada, o time mandante e visitante, a fase do campeonato, se regular $1^{\circ}$ ou $2^{\circ}$ turnos, além de oitavas, quartas, semi e finais dos playoffs, e o resultado do jogo.

\section{Resultados e Discussão}

$\mathrm{Na}$ tabela 1 apresentamos os resultados dos indicadores técnicos que apresentaram maiores diferenças entre as temporadas. As \% referem-se as eficiências de acertos;
LL são os lances livres; 2Ps e 3Ps aos arremessos de quadra; $\mathrm{C}$ a convertido; $\mathrm{T}$ a total; $\mathrm{M}$ a média; TT a totais tentados; TC a totais convertidos; $\mathrm{R}$ a rebote; As a assistências; BR a bolas roubadas; e FC a faltas cometidas.

Tabela 1: Principais diferenças encontradas nos indicadores técnicos entre as temporadas de 2008/09 a 2011/12

\begin{tabular}{|l|c|c|c|c|}
\hline & $\mathbf{2 0 0 8 / 0 9}$ & $\mathbf{2 0 0 9 / 1 0}$ & $\mathbf{2 0 1 0 / 1 1}$ & $\mathbf{2 0 1 1 / 1 2}$ \\
\hline \% LLC & 72,3 & 72,8 & 75,6 & 77,4 \\
\hline \% 2PtC & 49,6 & 49,7 & 51,5 & 51,7 \\
\hline \% 2PtsT & 44,8 & 44,9 & 46,6 & 48,2 \\
\hline M3PtsTT & 23,3 & 24,1 & 22,5 & 20,9 \\
\hline M3PtsTC & 8,1 & 8,7 & 7,8 & 7,4 \\
\hline M2PtsTT & 37,6 & 38,0 & 38,5 & 39,3 \\
\hline M2PtsTC & 20,1 & 20,4 & 20,7 & 20,9 \\
\hline
\end{tabular}

As diferenças principais mostram a evolução nos acertos de arremessos de 2 pontos e lances livres com aumento no número de tentativas, e uma diminuição nos acertos e tentativas das bolas de 3 pontos. Isso pode ser creditado a mudança da distância da linha de 3 pontos que ocorreu na temporada 2010/11.

\section{Conclusão}

O trabalho permitiu o envolvimento das alunas ensino médio em um processo de pesquisa científica, além do aprendizado de novas ferramentas e processos de organização e validação de dados, de descritores estatísticos e de análise e apresentação de resultados.

O trabalho mostrou as principais diferenças entre os indicadores técnicos que produzem pontos no jogo de basquetebol, além de produzir dados organizados para outras análises do grupo.

\section{Agradecimentos}

Conselho Nacional de Desenvolvimento Científico e Tecnológico CNPq.

${ }^{1}$ IBÁÑEZ, S., SAMPAIO, J., FEU, S. Basketball gamerelated statistics that discriminate between teams'season-long success. European Journal of Sport Science, November 2008; 8(6): 369372.

${ }^{2} \mathrm{GÓMEZ,} \mathrm{M.À.;} \mathrm{LORENZO,} \mathrm{A.;} \mathrm{SAMPAIO,} \mathrm{J.;} \mathrm{IBÁÑEZ,} \mathrm{S.J.;} \mathrm{ORTEGA,}$ E.; Game-Related Statistics that Discriminated Winning and Losing Teams from the Spanish Men's Professional Basketball Teams. Coll. Antropol v.32, n.2, p. 451-456, 2008

${ }^{3}$ GARCÍA, J., IBÁÑNEZ, S., CAÑADAS, M., ANTÚNEZ, A. Complex system theory in team sports. example in 5 on 5 basketball contest. Revista de Psicología del Deporte. Vol. 22, núm. 1, pp. 209-213. 2013. 